\title{
PENGARUH PELATIHAN RESUSITASI JANTUNG PARU (RJP) TERHADAP TINGKAT PENGETAHUAN PADA SISWA KELAS X DI SMA N 1 KARANGANOM KLATEN
}

\author{
Alga Febriana $\mathrm{H}^{1}$, Yuniar Ika Fajarini ${ }^{2}$, Akbar Amin Abdullah ${ }^{3}$ \\ Prodi S1 Keperawatan STIKES Duta Gama Klaten
}

\begin{abstract}
ABSTRAK
Latar Belakang: Henti jantung dapat terjadi dimana saja dan kapan saja. Pertolongan pertama pada korban henti jantung adalah melakukan resusitasi jantung paru. Resusitasi jantung paru tidak hanya dilakukan oleh tenaga nedis atau paramedis, tetapi masyarakat yang sudah terlatih mampu memberikan pertolongan sampai tenaga medis datang ke lokasi korban henti jantung.

Tujuan: Untuk mengetahui pengaruh pelatihan resusitasi jantung paru terhadap tingkat pengetahuan pada siswa kelas X di SMA N 1 Karanganom Klaten.

Metode Penelitian: Penelitian ini merupakan penelitian quasy-eksperiment design dengan menggunakan desain one group pretest-posttest. Sampel dalam penelitian ini adalah siswa kelas X SMA N 1 Karanganom Klaten yang berjumlah 24 siswa. Analisis data diuji menggunakan Uji Wilcoxon.

Hasil: Hasil uji statistik sebelum dan sesudah menunjukkan bahwa pelatihan resusitasi jantung paru sangat mempengaruhi tingkat pengetahuan siswa tentang penanganan pertama korban henti jantung, dengan nilai pengetahuan siswa sebelum diberikan pelatihan adalah dalam kategori baik sebanyak 2 responden setelah diberikan pelatihan pengetahuan siswa terjadi peningkatan sebanyak 23 berpengetahuan dalam kategori baik.

Kesimpulan: Terdapat pengaruh pelatihan resusitasi jantung paru terhadap tingkat pengetahuan pada siswa kelas $X$ di SMA $N 1$ Karanganom Klaten $p=0,000(p<0,05)$, sehingga penelitian ini dapat menambah wawasan responden dalam menangani korban henti jantung.
\end{abstract}

Kata kunci: pelatihan, siswa, resusitasi jantung paru

${ }^{1}$ Mahasiswa

${ }^{2}$ Pembimbing I

${ }^{3}$ Pembimbing II

\section{ABSTRACT}

Background: Cardiac arrest can occurred whenever and wherever. The first aid to patient of cardiac arrest is cardiopulmonary resuscitation. Cardiopulmonary resuscitation is not necessarily done by paramedic, but it can be also by trained non-paramedic that can give help until the paramedic arrives in location patient of cardiac arrest.

Objective: The objective of this study is to know the effect of cardiopulmonary resuscitation training on the level of knowledge in class $X$ students at SMA N 1 Karanganom Klaten.

Research Method: This research is a quasy-eksperiment design by using one group pretest-posttes design. The samples of this research were 24 students of the tenth grade in senior high school 1 Karanganom Klaten. The data were analyzed by using Uji Wilcoxon.

Result: Statistical test result before and after showed that cardiopulmonary resuscitation training greatly affects the level of students knowledge about the first aid to patient of cardiac arrest, with the value of student knowledge before being given training $s$ in good category as many as 2 respondents after being given training student knowledge there was an increase knowledge in good category as much 23 respondents.

Conclusion: There is an influence of cardiopulmonary resuscitation training on the level of knowledge in class $X$ students at SMA $N 1$ Karanganom Klaten $p=0,000(p<0,05)$, with the result this research is expected can be add the perception of respondents in dealing with victims of cardiac arrest. 


\section{PENDAHULUAN}

Kegawatdaruratan secara umum adalah suatu keadaan seseorang yang berada pada suatu kondisi yang mengancam hidupnya dan memerlukan pertolongan pertama. Pertolongan pertama ini berguna untuk menghindari kecacatan dan kematian saat seseorang berada pada kondisi kegawatdaruratan (Nursana, 2013).

Tim medis dan petugas kesehatan mempunyai tanggung jawab masalah kegawatdaruratan karena dapat terjadi dimana saja dan kapan saja. Kondisi kegawatdaruratan dapat terjadi pada daerah yang jauh dari keberadaan petugas kesehatan. Sehingga peran serta masyarakat untuk membantu korban dalam keadaan kegawatdaruratan menjadi sangat penting sebelum ditangani oleh petugas kesehatan (Sudiharto, 2011).

Salah satu keadaan kegawatdaruratan diantaranya adalah serangan jantung. World Health Organization (WHO) menyebutkan bahwa serangan jantung masih menjadi pembunuh nomor satu di negara maju maupun negara berkembang. Serangan jantung merupakan kondisi kegawatdaruratan yang mengakibatkan terjadinya henti jantung (Junaidi, 2011).

Kasus henti jantung di Indonesia sendiri belum diketahui data yang jelas mengenai jumlah pravelensi kejadian henti jantung dikehidupan sehari-hari atau di luar rumah sakit, namun diperkirakan sekitar 10.000 warga per tahun atau kurang lebih 30 orang per hari mengalami henti jantung. Kejadian terbanyak dialami oleh penderita jantung koroner. Kematian yang disebabkan oleh penyakit jantung koroner dan stroke sehingga mengalami henti jantung diperkirakan akan terus meningkat mencapai 23,3 juta kematian pada tahun 2030 (Depkes, 2014).

Kejadian henti jantung di Jawa Tengah belum diketahui data pastinya, namun angka kejadian seseorang yang terkena penyakit jantung koroner berdasarkan diagnosis dokter sebesar 120.447 kasus. Berdasarkan diagnosis dan gejala, estimasi jumlah penderita penyakit jantung koroner sebesar 337.252 kasus (Depkes, 2014).

Pertolongan pertama yang tepat dalam menangani kasus henti jantung atau cardiac arrest adalah Basic Life Support yang lebih dikenal dengan Bantuan Hidup Dasar (BHD). Salah satu intervensi yang dilakukan dalam Basic Life Support adalah Cardio Pulmonary Resusitation (CPR) atau biasa disebut Resusitasi Jantung Paru (RJP). Resusitasi Jantung Paru bertujuan untuk mengembalikan sirkulasi spontan dan mempertahankan fungsi vital organ pada korban henti jantung dan henti nafas dengan melakukan pemberian kompresi dada dan bantuan nafas (Hardisman, 
2014). Salah satu lapisan masyarakat yang dapat diberikan pendidikan kesehatan dalam upaya pemberian pertolongan pertama adalah remaja. Remaja adalah salah satu bagian dari masyarakat awam berjumlah sekitar 1,1 miliar penduduk dunia (WHO, 2010). Jumlah penduduk Indonesia pada tahun 2010 adalah 237,6 juta jiwa. Jumlah prosentase remaja Indonesia adalah sekitar $26,67 \%$ dari jumlah semua penduduk Indonesia atau 63,4 juta jiwa adalah remaja (BKKBN, 2014). Menurut Meissner (2012) menyatakan bahwa anak berusia 13 sampai 14 tahun di Jerman telah mampu melakukan tindakan RJP dengan baik, sama baiknya yang dilakukan orang dewasa. Remaja di Indonesia yang tergolong siswa setingkat sekolah menengah atas (SMA) alangkah lebih baiknya dapat melakukan tindakan RJP dengan baik dan benar. Pemberian pelatihan RJP pada siswa SMA dapat menambah wawasan dan pengetahuan para siswa. Pemberian pelatihan RJP merupakan hal yang sangat penting dan bermanfaat bagi peningkatan jumlah orang yang terlatih dalam penangan pertolongan pertama BHD sehingga dapat menjadi bystander di lingkungannya masingmasing. Semua lapisan masyarakat seharusnya diajarkan tentang bantuan hidup dasar. Jumlah siswa SMA yang mengetahui tentang bantuan hidup dasar hanya siswa yang mempunyai latar belakang pernah mengikuti ektrakurikuler Palang Merah Remaja (PMR) sedangkan tidak semua siswa di SMA mengikuti ekstrakurikuler tersebut (Mulyadi, 2016).

Shinta (2017), menyatakan bahwa di SMA Negeri 9 Binsus Manado tentang pengaruh simulasi tindakan resusitasi jantung paru terhadap tingkat motivasi siswa menolong korban henti jantung menyebutkan bahwa ada pengaruh pemberian simulasi tindakan resusitasi jantung paru terhadap tingkat motivasi siswa menolong korban henti jantung ( $p$ value $=0,00)$.

Berdasarkan hasil studi pendahuluan yang dilakukan di SMA N 1 Karanganom Klaten mengenai pengetahuan RJP didapatkan hasil bahwa 4 siswa diketahui belum mengerti tentang RJP dan belum pernah dilakukan pelatihan RJP. Berdasarkan latar belakang diatas, peneliti tertarik untuk melakukan penelitian dengan judul "Pengaruh Pelatihan Resusitasi Jantung Paru (RJP) Terhadap Tingkat Pengetahuan Siswa kelas $\mathrm{X}$ di SMA N 1 Karanganom."

\section{METODE PENELITIAN}

Jenis penelitian ini adalah quasy eksperiment dengan desain penelitian one grup pretest posstest. Populasinya adalah semua siswa kelas $\mathrm{X}$ di SMA $\mathrm{N} 1$ Karanganom Klaten yang berjumlah 394 siswa. Sampel penelitian sebanyak 24 
responden menggunakan kuesioner tertutup.

\section{HASIL DAN PEMBAHASAN}

\section{HASIL PENELITIAN}

\section{Karakteristik Responden (umur)}

Tabel 4.1 Karakteristik responden berdasarkan umur (n:24)

\begin{tabular}{cccc}
\hline No & Umur & Frekuensi & Persentase $(\%)$ \\
\hline 1 & 14 tahun & 2 & $8,3 \%$ \\
2 & 15 tahun & 16 & $66,7 \%$ \\
3 & 16 tahun & 6 & $25 \%$ \\
& Total & 24 & $100 \%$ \\
\hline \multicolumn{3}{c}{ Sumber : Data primer 2018 }
\end{tabular}

Berdasarkan tabel 4.1 diketahui bahwa responden yang paling banyak berumur 15 tahun sebanyak 16 responden $(66,7 \%)$, sedangkan yang paling sedikit responden berumur 14 tahun sebanyak 2 responden $(8,3 \%)$.

2. Karakteristik Responden (jenis kelamin)

Tabel 4.2 Karakteristik responden berdasarkan jenis kelamin (n:24)

\begin{tabular}{clcc}
\hline No & Jenis Kelamin Frekuensi & $\begin{array}{c}\text { Persentase } \\
(\%)\end{array}$ \\
\hline 1 & Laki-laki & 18 & $75 \%$ \\
2 & Perempuan & 6 & $25 \%$ \\
& Total & 24 & $100 \%$ \\
\hline \multicolumn{3}{c}{ Sumber : Data primer 2018}
\end{tabular}

Berdasarkan tabel 4.2 diketahui bahwa responden yang paling banyak berjenis kelamin laki-laki sebanyak 18 responden $(75 \%)$, sedangkan yang berjenis kelamin perempuan sebanyak 6 responden $(25 \%)$.

3. Pengetahuan Sebelum dilakukan Pelatihan

Tabel 4.3 Karakteristik responden berdasarkan pengetahuan sebelum dilakukan pelatihan (n:24)

\begin{tabular}{clcc}
\hline No & Pengetahuan & Frekuensi & $\begin{array}{c}\text { Persentase } \\
(\%)\end{array}$ \\
\hline 1 & Baik & 2 & $8,3 \%$ \\
2 & Cukup & 16 & $66,7 \%$ \\
\hline
\end{tabular}

\begin{tabular}{cccc}
\hline 3 & Kurang & 6 & $25 \%$ \\
& Total & 24 & $100 \%$ \\
\hline
\end{tabular}

Sumber : Data primer 2018

Berdasarkan tabel 4.3 diketahui bahwa paling banyak responden memiliki pengetahuan cukup sebanyak 16 responden $(66,7 \%)$, sedangkan yang paling sedikit responden memiliki pengetahuan baik sebanyak 2 responden $(8,3 \%)$.

\section{Pengetahuan Sesudah dilakukan Pelatihan}

Tabel 4.3 Karakteristik responden berdasarkan pengetahuan sesudah dilakukan pelatihan (n:24)

\begin{tabular}{clcc}
\hline No & Pengetahuan & Frekuensi & $\begin{array}{c}\text { Persentase } \\
(\%)\end{array}$ \\
\hline 1 & Baik & 23 & $95,8 \%$ \\
2 & Cukup & 1 & $4,2 \%$ \\
3 & Kurang & 0 & $0 \%$ \\
\multicolumn{2}{c}{ Total } & 24 & $100 \%$ \\
\hline \multicolumn{2}{l}{ Sumber : Data primer 2018 }
\end{tabular}

Berdasarkan tabel 4.4 diketahui bahwa paling banyak responden memiliki pengetahuan baik sebanyak 23 responden $\quad(95,8 \%)$, sedangkan responden yang memiliki pengetahuan cukup sebanyak 1 responden (4,2\%). Responden dengan pengetahuan kurang sudah tidak ada $(0 \%)$.

\section{Analisis Bivariate}

\section{a. Uji Wilcoxon}

Table 4.5 Pengaruh pelatihan RJP terhadap tingkat pengetahuan pada siswa kelas $\mathrm{X}$ di SMA N I Karanganom Klaten

\begin{tabular}{ccc}
\hline & N & P-value \\
\hline Pretest & 24 & 0,000 \\
Posttest & 24 & \\
\hline
\end{tabular}

Berdasarkan uji statistik dengan Wilcoxon didapatkan hasil bahwa ada 
pengaruh pelatihan RJP terhadap tingkat pengetahuan pada siswa kelas $X$ di SMA $\mathrm{N} 1$ Karanganom Klaten dengan nilai $p$ value $=0,000(p<0,05)$.

\section{PEMBAHASAN}

Hasil penelitian mengenai pengetahuan siswa tentang RJP sebelum diberi pelatihan sebagian besar adalah adalah cukup sebanyak 16 responden $(66,7 \%)$, siswa yang berpengetahuan kurang sebanyak 6 responden (25\%), sedangkan siswa dengan pengetahuan baik hanya 2 responden $(8,3 \%)$. Keadaan ini disebabkan karena sedikitnya responden yang mendapatkan informasi tentang RJP, karena dengan banyaknya informasi yang diperoleh maka seseorang akan memiliki pengetahuan. Kurangnya informasi yang dimiliki responden disebabkan kurangnya pemberian pendidikan kesehatan yang mencakup pelatihan.

Menurut Notoatmodjo (2003) dalam buku Wawan dkk (2011) pengetahuan merupakan hasil tahu dan ini terjadi setelah orang mengadakan pengidraan terhadap suatu objek tertentu. Pengindraan suatu objek terjadi melalui panca indra manusia yakni penglihatan, pendengaran, penciuman, rasa dan raba dengan sendiri. Pada waktu pengindraan sampai menghasilkan pengetahuan tersebut sangat dipengaruhi oleh intensitas perhatian persepsi terhadap obyek.
Pengetahuan cukup yang dimiliki siswa tentang RJP menunjukkan bahwa pentingnya pemberian pelatihan RJP kepada siswa kelas $\mathrm{X}$ di SMA $\mathrm{N} 1$ Karanganom Klaten sehingga pengetahuan siswa dapat diperoleh hasil yang optimal. Pelatihan memiliki peran yang besar dalam memperbaiki pengetahuan responden. Pada penelitian ini terlihat bahwa pengetahuan responden dalam kategori baik terjadi peningkatan sebanyak 23 responden $(95,8 \%)$, pengetahuan dalam kategori cukup sebanyak 1 orang $(4,2 \%)$, sedangkan pengetahuan responden dalam kategori kurang sudah tidak ada (0\%). Hal tersebut menunjukkan bahwa pelatihan memiliki peran yang sangat besar dalam meningkatkan pengetahuan dan bertujuan untuk meningkatkan pelayanan kesehatan. Peran pelatihan dalam pelayanan kesehatan dimaksudkan untuk melakukan perbaikan kesehatan masyarakat (Yuliantari dkk, 2014).

Analisis bivariate menggunakan uji Wilcoxon diperoleh hasil yang signifikan $(\mathrm{p}=0,000)$ yang berarti nilai $\mathrm{p}<0,05$. Hipotesis ini dapat diartikan bahwa Ho ditolak dan $\mathrm{Ha}$ diterima yaitu ada perbedaan antara sebelum dan sesudah dilakukan pelatihan RJP terhadap tingkat pengetahuan pada siswa kelas $\mathrm{X}$ di SMA N 1 Karanganom Klaten.

Hasil menunjukkan terjadi peningkatan pengetahuan siswa dapat 
dilihat sebelum pelatihan $8,3 \%$ pengetahuan baik menjadi $95,8 \%$ dan penurunan pengetahuan yang cukup dari $66,7 \%$ menjadi $4,2 \%$. Pengetahuan dalam kategori kurang dari $25 \%$ menjadi $0 \%$.

Peningkatan pengetahuan pada siswa kelas X di SMA N 1 Karanganom Klaten disebabkan karena ada informasi yang memberikan pengetahuan tentang penting melakukan resusitasi jantung paru saat menemukan seseorang yang sedang mengalami henti jantung dan henti nafas. Pelatihan diberikan dengan metode ceramah dan tanya jawab serta memberikan materi tentang Resusitasi Jantung Paru (RJP). Pemberian teori dan praktik dimaksudkan dapat memberikan pengetahuan, informasi dan pengalaman yang lebih banyak. Tingkat pengetahuan menunjukkan adanya perubahan sesudah diberikan pelatihan. Hasil ini sesuai dengan teori Supriyadi (2013) tentang cara seorang siswa dalam memperoleh pembelajaran ada 3 yaitu: visual, audio, dan kinestik. Pelatihan RJP adalah suatu pembelajaran dalam metode praktik, jadi seorang siswa mampu melihat saat pelatih mempraktikkan, mampu mendengarkan materi saat pelatih memberikan materi dan mampu melakukan pelatihan RJP saat mereka diberikan pelatihan RJP.

\section{KESIMPULAN}

Berdasarkan hasil penelitian Pengaruh Pelatihan Resusitasi Jantung
Paru (RJP) terhadap Tingkat Pengetahuan Pada Siswa Kelas X di SMA N 1 Karanganom Klaten didapatkan kesimpulan sebagai berikut:

1. Pengetahuan siswa kelas $X$ mengenai RJP, sebelum dilakukan pelatihan di SMA N 1 Karanganom Klaten dengan pengetahuan dalam kategori baik hanya 2 responden $(8,3 \%)$.

2. Pengetahuan siswa kelas $\mathrm{X}$ mengenai RJP, setelah dilakukan pelatihan di SMA N 1 Karanganom Klaten dengan pengetahuan dalam kategori baik sebanyak 23 responden $(95,8 \%)$.

3. Terdapat perbedaan pengetahuan siswa kelas X di SMA N 1 Karanganom Klaten sebelum diberikan pelatihan dan setelah dilakukan pelatihan.

4. Terdapat Pengaruh Pelatihan Resusitasi Jantung Paru (RJP) Terhadap Tingkat Pengetahuan Siswa Kelas X di SMA N 1 Karanganom Klaten ditandai dengan nilai $p=0,000(p<0,05)$.

\section{DAFTAR PUSTAKA}

American College of Emergency Physicians (ACEP). 2013. Emergency Medical Treatment and Labor (www.acep.org/Newsmedia-top-banner/EMTALA di unduhtgl 10 Januari 2018 pukul 08.55 WIB)

American Heart Association. 2010. CPR Overview: American Heart Association Guidelines for Cardiopulmonary Resuscitation 
and Emergency Cardiovaskular Care. AHA Journals

Berg RA, Hemphill R, Abella BS, et al. 2010. Part 5: Adult Basic Life Support: American Heart Association Guidelines For Cardiopulmonary Resuscitation and Emergency Cardiovascular Care.

Hardisman. 2014. Gawat Darurat Medis Praktis.Yogyakarta: Gosyen Publishing.

Hastono, S. P dan Sabri, L.2013. Statistik Kesehatan. Jakarta: Rajawali Pers. Cetakan ketujuh.

Hidayat, A. A. A.2011. Metode Penelitian Keperawatan dan Teknik Analisis Data. Jakarta: Salemba Medika.

Kementrian Kesehatan RI, 2014. Profil Kesehatan Indonesia Tahun 2014. (www.depkes.go.id. Di unduh tgl 17 Januari 2018 pukul 20.05 WIB).

2014. Profil Kesehatan
Kabupaten. Klaten; dinkes
(www.depkes.go.id. di unduh tgl
17 Januari 2017 pukul 20.16 WIB).

Notoatmodjo, S. 2010. Metodologi Penelitian Kesehatan. Jakarta: Rineka Cipta.

Pusbankes118.2013. Penanggulangan Penderita Gawat Darurat (PPGD), Basic Trauma And Cardiac Support (BTCLS). Yogyakarta: Persi DIY.

Shinta.2017. Pengaruh Simulasi Tindakan Resusitasi Jantung Paru (RJP) Terhadap Tingkat Motivasi Siswa Menolong Korban Henti Jantung di SMA Negeri 9 Binsus Manado

St John, A. 2005.First Aid Manual. United Kingdom: St John
Sudiharto, S. 2011. Basic Trauma Cardiac Life Support. Jakarta: CV. SagungSeto

Sugiyono.2011. Metode Penelitian Pendidikan. Bandung: Alfabeta

Thoyyibah, D. 2014. Pengaruh Pelatihan Bantuan Hidup Dasar Pada Remaja terhadap Tingkat Motivasi Menolong Korban HentiJantung:(www.thesis.umy.a c.id/datapublik/t34049.pdf di unduh tgl 10 Januari 2018 pukul 09.22 WIB)

Wawan, A dan M Dewi.2011. Teori dan Pengukuran Pengetahuan, Sikap, dan Perilaku Manusia. Yogyakarta: Nuha Medika.

World Health Organisation (WHO). 2010. OrientationP rogramme on Adolescent Health Care Providers. (www.who.int di unduh tgl 10 Januari 2018 pukul 09.00 WIB)

Wawan, A dan M Dewi.2011. Teori dan Pengukuran Pengetahuan, Sikap, dan Perilaku Manusia. Yogyakarta: Nuha Medika. 